\title{
Bonding Strength of Luting Cement to Zirconia-Based Ceramic Under Different Surface Treatments
}

\author{
Fabio Mendes ${ }^{1}$ Mauricio M. Zanini ${ }^{2} \quad$ Jamille Favarão $^{2}$ Veridiana Camilotti ${ }^{3} \quad$ Mario A. C. Sinhoreti \\ Marcio J. Mendonça ${ }^{1}$ Simonides Consani ${ }^{2}$
}

${ }^{1}$ Department of Prosthodontics, Western State University of Paraná - Dental School, Cascavel, Paraná, Brazil

2Department of Restorative Dentistry, Dental Materials Division, Piracicaba Dental School, University of Campinas, Piracicaba, São Paulo, Brazil

${ }^{3}$ Department of Restorative Dentistry, Western State University of Paraná-UNIOESTE, Dental School, Cascavel, Paraná, Brazil

Eur J Dent 2019;13:222-228

\begin{abstract}
Address for correspondence Marcio José Mendonça, DDS, MS, PhD, Rua Universitária, 2069, Cascavel 85808-457, Paraná, Brazil (e-mail: dr.mendonca@uol.com.br).
\end{abstract}

\begin{abstract}
Keywords

- ceramics

- shear strength

- dental prostheses

- zirconium

Objectives The aim of this study was to evaluate the bonding strength of self-adhesive luting cement to zirconia under different surface treatments.

Materials and Methods Thirty-two zirconia samples were randomly divided into eight experimental groups based on the surface treatment employed (Control: no surface treatment; PMM: wear with diamond bur; JAT: blasting with glass beads; PMA: wear with a medium-roughness milling machine; Primer: primer application on the surface without treatment; PMM +Primer: PMM treatment plus primer application; JAT+Primer: JAT treatment plus primer application; and PMA+Primer: PMA treatment plus primer application). Cement cylinders were built on the ceramic surfaces, and the groups were subdivided according to the storage time employed (i.e., 24 hours or 60 days). After storage, the samples were subjected to microshear testing.

Statistical Analysis The Kruskal-Wallis test followed by the Dunn test was employed for comparison between the groups $(p<0.05)$.

Results The PMM group yielded the optimal results and the mean values increased after both storage times following the primer application. The Control, PMA, and JAT groups gave similar results after 24 hours, while the JAT group gave superior results following primer application over this storage time. After 60 days of storage, all groups gave improved results following chemical treatment with a primer.

Conclusion It was concluded that mechanical preparation using the diamond bur followed by primer application significantly improved the bond strength between the ceramic and the luting cement.
\end{abstract}

\section{Introduction}

Zirconia is fully biocompatible and is used quite often in the medical field (for auditory, finger and hip prostheses) and in dentistry. Zirconia-based ceramics are among the most resistant aesthetic materials commonly used in indirect single-unit restorations, fixed partial dentures, indirect restorations, and more recently, monolithic restorations. ${ }^{1}$ Several variations in zirconia have been developed, with each new material intended to improve upon the quality of previous versions. Recently, the use of monolithic yttria-stabilized tetragonal zirconia polycrystal (Y-TZP) for indirect restorations has been developed to overcome the problems of veneered zirconia fixed dental prostheses. ${ }^{2}$ The high resistance of such ceramics can be attributed to the improved mechanical properties of Y-TZP. ${ }^{1}$ Zirconia is a polymorphic 
material that exists in nature in three forms, namely the monoclinic, tetragonal, and cubic forms. Upon the addition of yttrium oxide (yttria), zirconium oxide particles are stabilized in the tetragonal phase at room temperature. However, the tetragonal-to-monoclinic phase transformation can still occur when the Y-TZP ceramic is subjected to stimuli, such as oral masticatory forces, exposure to different temperatures, $\mathrm{pH}$ changes, and oral microorganisms. ${ }^{3}$

In addition, the Y-TZP ceramic exhibits a high crystalline content and the absence of a glass phase, which renders adhesion to this material a challenge. Thus, the adhesion of resin cement to high strength zirconia ceramics is difficult, and acid etching or silanization cannot be expected to improve adhesion because the ceramics are resistant to inert acids. ${ }^{4}$ Indeed, as even the use of hydrofluoric acid is unable to promote micromechanical retention or render the surface chemically active, ${ }^{5}$ several methods have been examined to promote stable bonding between ceramics and resin cements. ${ }^{6,7}$

In this context, several surface treatment methods have been proposed, including abrasion by air-blasting with aluminum oxide and silica particles, laser irradiation by erbium-doped yttrium aluminum garnet (Er:YAG), neodymium-doped yttrium aluminum garnet (Nd:YAG), or carbon dioxide, silica coating or silanization, and the use of phosphate acid monomers. ${ }^{8,9}$ However, many of these treatment methods are complex due to requirements for specialist equipment or technical expertise. These methods are usually expensive and can cause damages to the infrastructure of the prosthesis, in addition to promoting the phase transformation to the less stable monoclinic phase.

The development of alternative and more facile mechanical treatments for application to zirconia surfaces would therefore be desirable to increase the bonding strength to resin cement and for the widespread application in routine oral rehabilitation treatments. Thus, the use of diamond burs on the inner surface of the pre-sintering zirconia infrastructure would be an attempt to improve the mechanical retention of the resin cement without causing phase transformation in the zirconia.

Few studies have investigated the surface treatment of zirconia ceramic before sintering. ${ }^{10-12}$ Thus, the aim of this study was to evaluate several surface roughening treatments (i.e., diamond bur abrasion, glass bead blasting, and mechanical milling) and the use of a ceramic primer on the surface of a Y-TZP ceramic, on the bond strength of a self-adhesive resin cement after 24 hours and 60 days of storage. The null hypothesis is that different mechanical and chemical surface treatments would not influence the bonding strength to zirconia ceramics.

\section{Materials and Methods}

The materials used throughout this study are outlined in - Table 1.

\section{Sample Calculations}

The sample calculations were based on the probability distributions of family F, with a delineation of repeated families, and with interaction within and between the factors. The effect size employed was 0.15 , in addition to a type 1 error $(\alpha)$ of 0.05 , and an analysis power of 0.95 , which guaranteed a minimum of 162 specimens. A total of 192 specimens were prepared (12 per experimental group). The samples were calculated using the GPower software (version 3.1.9.2University of Düsseldorf, Düsseldorf, Germany).

\section{Zirconia Specimen Preparation}

Thirty-two blocks of zirconia $\left(\mathrm{ZrO}_{2} \cdot \mathrm{Y}_{2} \mathrm{O}_{3}\right)$ exhibiting a polycrystalline tetragonal structure (ICE Zirkon Translucent-Zirkonzahn SRL; Gais, Italy) and measuring $10 \times 10 \times 3 \mathrm{~mm}$, were prepared by means of virtual planning using the Zirkonzahn Fräsen software, version 2.0.9. (Zirkonzahn SRL, Gais, Italy) and employing the dimensions specified by the M 5 milling machine software with $5+1$ axes and two motors (Zirkonzahn SRL, Gais, Italy). Six cementation sites were determined on each ceramic block ( $\mathbf{- F i g s .} \mathbf{1}$ and $\mathbf{2}$ ).

After milling and preparation of the surfaces according to the experimental groups, the ceramic blocks were sintered in a Zirkonofen 600 oven (Zirkonzahn SRL, Gais, Italy) at $1550^{\circ} \mathrm{C}$ for 12 hours.

The zirconia blocks were embedded in acrylic resin Vipi Flash (Vipi, São Paulo, Brazil) in PVC tubes (2 cm diameter, $3 \mathrm{~cm}$ height). The ceramic block was then cleaned by means

Table 1 Compositions of the materials

\begin{tabular}{|l|l|l|}
\hline Commercial name & \multicolumn{1}{|c|}{ Composition } & \multicolumn{1}{|c|}{ Manufacturer and batch number } \\
\hline ICE Zirkon Translucent & $\mathrm{ZrO}_{2}, \mathrm{Y}_{2} \mathrm{O}_{3}, \mathrm{Al}_{2} \mathrm{O}_{3}, \mathrm{SiO}_{2}, \mathrm{Fe}_{2} \mathrm{O}_{3}, \mathrm{Na}_{2} \mathrm{O}$ & $\begin{array}{l}\text { Zirkonzahn SRL } \\
\text { Gais, Italy } \\
\text { ZB4119Q and ZB3264L }\end{array}$ \\
\hline Monobond Plus & $\begin{array}{l}\text { Alcoholic solution of silane methacrylate, phosphoric acid meth- } \\
\text { acrylate, and sulfide methacrylate. }\end{array}$ & $\begin{array}{l}\text { Ivoclar Vivadent } \\
\text { AG, Schaan, Liechtenstein } \\
\text { T21454 }\end{array}$ \\
\hline Relyx U 200 & $\begin{array}{l}\text { Base paste: silane-treated glass powder, 2-propenoic acid, } \\
\text { 2-methyl 1m1-[1- (hydroxymethyl)-1,2-thanodly] ester, trieth- } \\
\text { ylene glycol dimethacrylate (TEGDMA), silane-treated silica, } \\
\text { glass, sodium persulfate and t-butyl per-3,5,5-trimethylhexa- } \\
\text { noate. Catalyst paste: silane-treated glass powder, substituted } \\
\text { dimethacrylate, silane-treated silica, sodium p-toluenesulfon- } \\
\text { ate, 1-benzyl-5-phenyl-baric acid, calcium salts, 1,12-dodecane } \\
\text { dimethacrylate, calcium hydroxide, and titanium dioxide. }\end{array}$ & $\begin{array}{l}\text { 3M-ESPE } \\
\text { St. Paul, Minnesota, United States }\end{array}$ \\
\hline
\end{tabular}




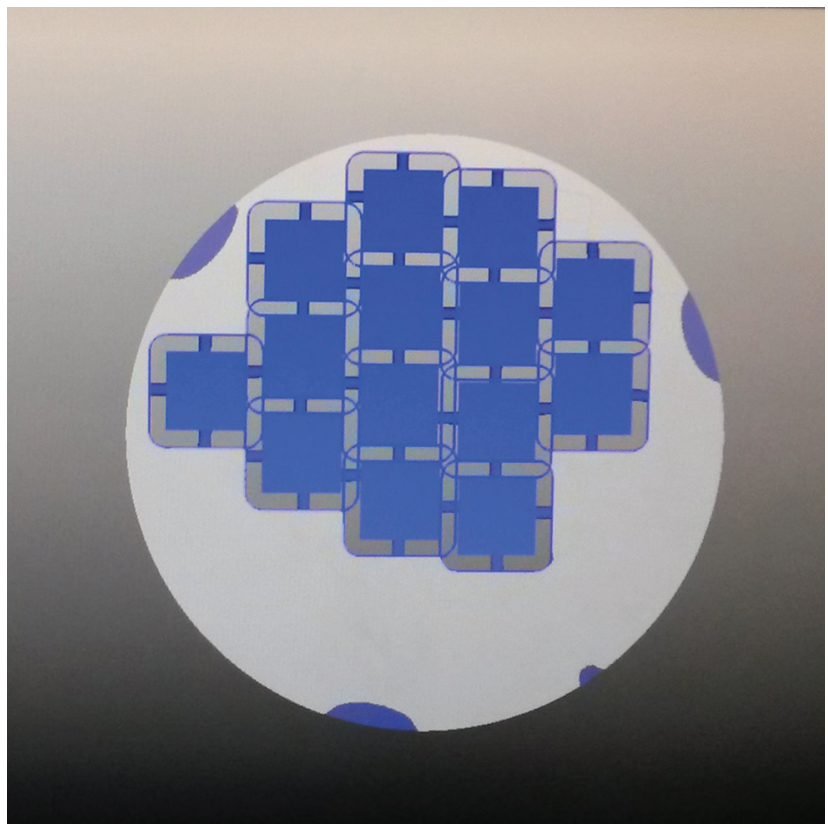

Fig. 1 Virtual planning of the blocks in Y-TZP. Y-TZP, yttria-stabilized tetragonal zirconia polycrystal

of ultrasonication in distilled water for 30 minutes prior to drying under a jet of air.

\section{Experimental Groups}

All samples were randomly divided into eight experimental groups based on the surface treatment employed. Each group was then divided into two subgroups according to the aging time employed, that is, 24 hours or 60 days ( $n=12$ ), as outlined in - Table 2 .

\section{Cementation Procedure}

Six 5/32-inch latex matrices (1 mm height, $1.6 \mathrm{~mm}$ internal diameter, Morelli, São Paulo, Brazil) were used for preparation of the resin cement cylinders. The matrices were stabilized on the ceramic blocks and fixed with cyanoacrylate-based glue (SuperBonder, 3M, São Paulo, Brazil) in the cementation sites employed for the microshear strength test.

Subsequently, the matrix holes were filled using RelyX U200 self-adhesive resin cement (3M ESPE, St. Paul, Minnesota, United States), the latex matrix was covered with a polyester strip, and a cover glass was placed on top. The resulting assembly was maintained under digital pressure for $30 \mathrm{sec}-$ onds to remove any excess resin cement. Finally, photoactivation was performed using a Bluephase G2 curing unit (Ivoclar Vivadent; AG, Schaan, Liechtenstein) at $1200 \mathrm{~mW} / \mathrm{cm}^{2}$ for 30 seconds.

\section{Microshear Tests}

Prior to carrying out the microshear tests, all samples were stored in distilled water at $37^{\circ} \mathrm{C}$ for either 24 hours or 60 days according to their experimental groups. The microshear test was performed using an EMIC DL 200MF universal test machine (São José dos Pinhais, SP, Brazil). Each specimen

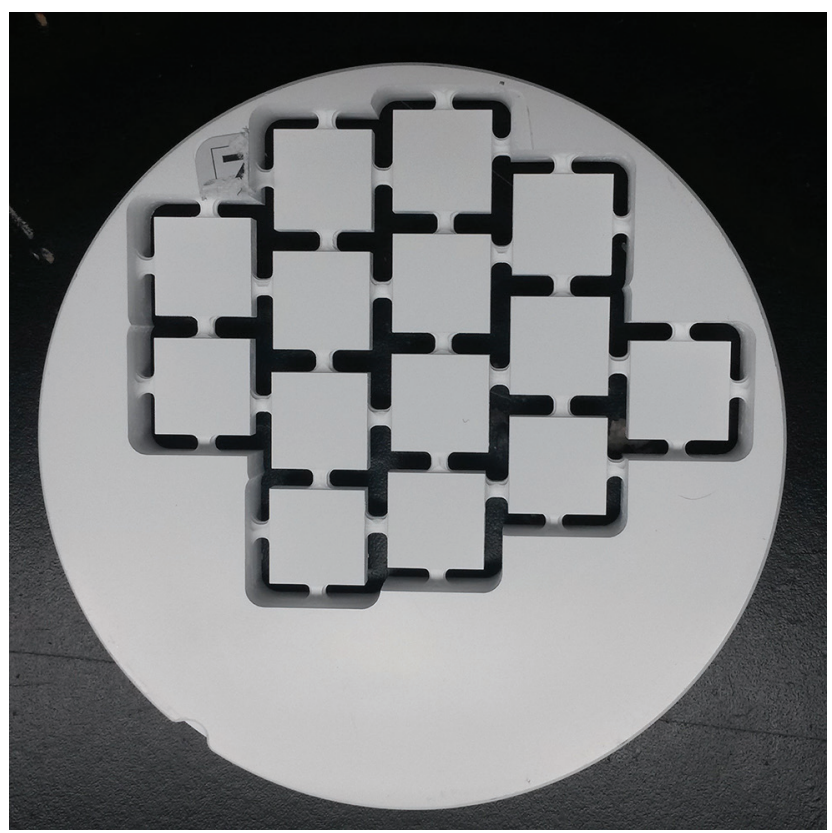

Fig. 2 The milling block prepared according to the virtual planning.

was positioned in a metal device on the machine, and a $\mathrm{NiCr}$ orthodontic wire $(0.25 \mathrm{~mm}$ circular section, Morelli, São Paulo, Brazil) was looped around the base of each cylinder prior to subjecting the specimen to a crosshead speed of $1 \mathrm{~mm} / \mathrm{min}$ until failure. The microshear bond strength (MPa) was then calculated as follows:

$$
\mathrm{Rc}=\mathrm{F} / \mathrm{A}
$$

where Rc is the microshear strength, $\mathrm{F}$ is the applied force, and $A$ is the bond area.

\section{Statistical Analysis}

The data were submitted to statistical analysis using Bioestat 5.3 software (Mamirauá Institute, AM, Brazil, 2007). Initially, the data were submitted to the Shapiro-Wilk test. As the data did not adhere to the normality curve, the Mann-Whitney U test $(p<0.05)$ was employed for comparison between two groups, while for other comparisons, the Kruskal-Wallis variance test was used, followed by the Dunn test to analyze the interactions between groups $(p<0.05)$.

\section{Results}

The mean values and standard deviations of the microshear bond strengths determined for the various experimental groups are listed in - Table 3 . As indicated by the results, primer application following storage for 60 days improved the bond strength independent of the mechanical conditioning technique employed. In contrast, improved bond strengths were only observed for the JAT and PMM groups following primer application and 24 hours storage.

Although no statistically significant differences were observed after 24 hours storage for the samples receiving no primer application, after 60 days, the PMM group showed 
Table 2 Experimental groups

\begin{tabular}{|c|c|c|}
\hline Group & Surface treatment & Storage \\
\hline \multirow[t]{2}{*}{ Control } & \multirow[t]{2}{*}{ Untreated surface } & $24 \mathrm{~h}$ \\
\hline & & $60 \mathrm{~d}$ \\
\hline \multirow[t]{2}{*}{ PMM } & \multirow{2}{*}{$\begin{array}{l}\text { Mechanical preparation for } 5 \text { seconds. The Pre-sintered surface was worn with a } 3101 \mathrm{~F} \\
\text { diamond bur (KG Sorensen, São Paulo, SP), using a contra angle low speed handpiece under } \\
\text { refrigeration and light manual pressure to standardize the roughness of the surface }\end{array}$} & $24 \mathrm{~h}$ \\
\hline & & $60 \mathrm{~d}$ \\
\hline \multirow[t]{2}{*}{ JAt } & \multirow{2}{*}{$\begin{array}{l}\text { Blasting: The post-sintered surface was worn by blasting using } 100 \mu \mathrm{m} \text { glass microspheres } \\
\text { (calcium carbonate and quartz) at an angle of } 90^{\circ} \text { and at a } 5 \mathrm{~mm} \text { distance and } 60 \mathrm{lb} \text { pressure } \\
\text { for } 10 \text { seconds }\end{array}$} & $24 \mathrm{~h}$ \\
\hline & & $60 \mathrm{~d}$ \\
\hline \multirow[t]{2}{*}{ PMA } & \multirow{2}{*}{$\begin{array}{l}\text { Automatic mechanical preparation with a milling machine: The pre-sintered surface was worn } \\
\text { with } 5+1 \text { axes and two motors (Zirkonzahn Gais), and the surface roughness was determined } \\
\text { using Zirkonzahn Fräsen software, version } 2.0 .9\end{array}$} & $24 \mathrm{~h}$ \\
\hline & & $60 \mathrm{~d}$ \\
\hline \multirow[t]{2}{*}{ Primer } & \multirow{2}{*}{$\begin{array}{l}\text { Primer application (Monobond Plus, Ivoclar Vivadent) on the untreated ceramic surface: } \\
\text { Active application was performed for } 5 \text { seconds using a microbrush on the surface, with a } \\
\text { waiting time of } 60 \text { seconds and removal of excess primer using an air jet }\end{array}$} & $24 \mathrm{~h}$ \\
\hline & & $60 d$ \\
\hline \multirow[t]{2}{*}{ PMM + primer } & \multirow{2}{*}{$\begin{array}{l}\text { Treatment of PMM + primer application (Monobond Plus, Ivoclar Vivadent): Active application } \\
\text { was performed for } 5 \text { second using a microbrush on the surface, with a waiting time of } \\
60 \text { second and removal of excess PMM and primer using an air jet }\end{array}$} & $24 \mathrm{~h}$ \\
\hline & & $60 d$ \\
\hline \multirow[t]{2}{*}{ PMM + primer } & \multirow{2}{*}{$\begin{array}{l}\text { Treatment of the JAT Group + primer application (Monobond Plus, Ivoclar Vivadent): Active } \\
\text { application was performed for } 5 \text { second using a microbrush on the surface, with a waiting } \\
\text { time of } 60 \text { second and removal of excess reagents using an air jet }\end{array}$} & $24 \mathrm{~h}$ \\
\hline & & $60 d$ \\
\hline \multirow[t]{2}{*}{ PMM + primer } & \multirow{2}{*}{$\begin{array}{l}\text { Treatment of WFP + primer application (Monobond Plus, Ivoclar Vivadent): Active application } \\
\text { was performed for } 5 \text { second using a microbrush on the surface, with a waiting time of } \\
60 \text { second and removal of excess reagents using an air jet }\end{array}$} & $24 \mathrm{~h}$ \\
\hline & & $60 \mathrm{~d}$ \\
\hline
\end{tabular}

Table 3 Mean values and standard deviations of the micro-shear bond strength (MPa) for the experimental groups according to the surface chemical treatment

\begin{tabular}{|l|l|l|l|l|}
\hline \multirow{2}{*}{ Aging time } & \multicolumn{3}{|c|}{ Surface treatment } & $p$-Value \\
\cline { 2 - 5 } & & Without primer & With primer \\
\hline \multirow{5}{*}{$24 \mathrm{~h}$} & Control & $6.00(1.62)$ & $6.50(1.40)$ & 0.5708 \\
\cline { 2 - 5 } & PMA & $6.22(0.67)$ & $7.31(2.37)$ & 0.5205 \\
\cline { 2 - 5 } & JAT & $3.89(0.91)$ & $13.26(2.68)$ & $0.0002^{\mathrm{a}}$ \\
\cline { 2 - 5 } & PMM & $9.82(1.03)$ & $20.26(2.21)$ & $0.0002^{\mathrm{a}}$ \\
\hline \multirow{3}{*}{$60 \mathrm{~d}$} & Control & $0.38(0.44)$ & $6.85(4.71)$ & $0.0002^{\mathrm{a}}$ \\
\cline { 2 - 5 } & PMA & $0.14(0.11)$ & $6.39(2.30)$ & $0.0002^{\mathrm{a}}$ \\
\cline { 2 - 5 } & JAT & $0.11(0.09)$ & $8.86(2.40)$ & $0.0002^{\mathrm{a}}$ \\
\hline & PMM & $3.14(0.86)$ & & $0.0002^{\mathrm{a}}$ \\
\hline
\end{tabular}

aStatistically significant differences, $p<0.05$.

a significantly higher bond strength than the other groups (-Fig. 3).

Furthermore, similar bond strengths were exhibited by the JAT, PMA, and Control groups following primer application and 24 hours storage, although these values were lower than those of the PMM group. After 60 days storage, lower values were obtained for the PMA group, and those of the PMM and Control groups were statically superior. Moreover, the JAT group presented similar results to all other groups following primer application and 60 days storage (-Fig. 4 ).

\section{Discussion}

To improve the bond strengths of the Y-TZP ceramic restorations, a range of mechanical and chemical surface treatments have been proposed. Importantly, we note that the null hypothesis was rejected, as we clearly confirmed that the combination of mechanical treatment and chemical conditioning with the Monobond Plus primer improved the bond strength of the Rely X U200 resin cement to the ceramic structure.

In our study, the storage/aging method consisted of immersion in distilled water, with thermocycling being 


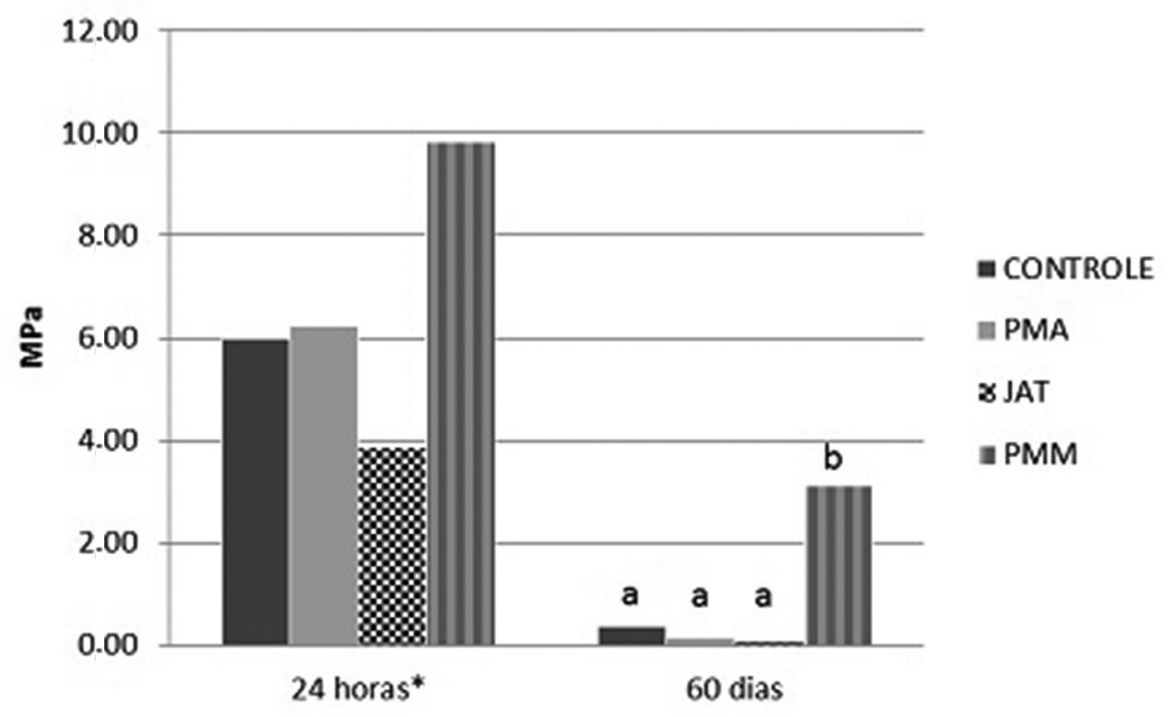

Fig. 3 Variation in the mean values of the microshear bond strengths (MPa) of the experimental groups without primer application upon variation in the pre-test storage time. ${ }^{*}$ No statistically significant differences were found $(p>0.05)$. Different letters represent statistically significant differences for analysis at the same storage times $(p<0.05)$.

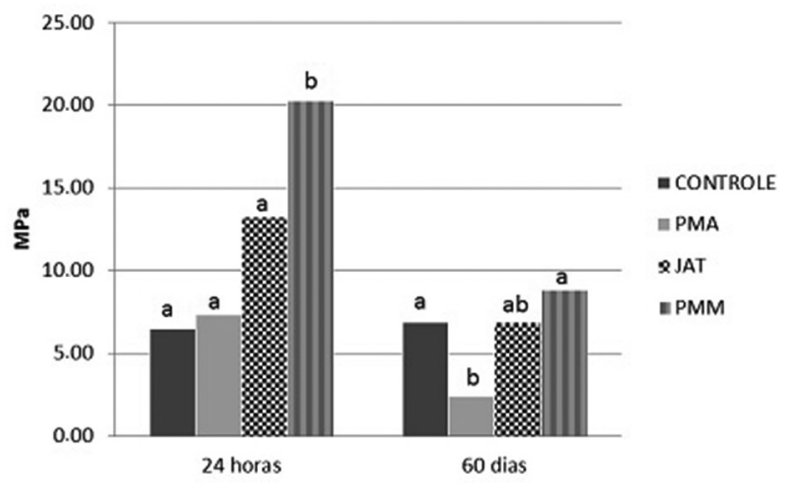

Fig. 4 Variation in the mean values of the microshear bond strengths (MPa) of the experimental groups with primer application upon variation in the pre-test storage time. Different letters represent statistically significant differences for analysis at the same storage times $(p<0.05)$.

avoided due to a greater correlation between the storage failure at $100 \%$ humidity and a stable temperature $(r=-0.4)$ than following thermocycling $(r=-0.15) .{ }^{13}$ In the case of thermocycling, a large number of cycles $(100,000)$ were suggested to produce a significant effect on the bonding surface, with this number of cycles representing approximately 3 months storage at $100 \%$ relative humidity. ${ }^{13,14}$ Considering the time required to carry out such large numbers of cycles and the equipment required for this purpose, storage in distilled water proves to be of great value due to its positive results and facile applicability.

As previously mentioned, the highest bond strength was achieved for the PMM mechanical treatment group, which employed the diamond bur abrasion method. During this process, the rotation employed, diamond tip granulation, the manual pressure exerted, and the presence or absence of refrigeration must be carefully considered. ${ }^{15}$ As such, although this process may be beneficial for bonding the resin cement to the ceramic, it may also lead to excessive stress concentration and phase transformation of the Y-TZP ceramics. In our case, the PMM group received treatment with a thin diamond bur, mounted at a contra angle low speed handpiece under refrigeration. This setup was based on previous studies that demonstrated that these characteristics are necessary for greater control of the abrasion, reducing defect formation, and lowering the risk of phase transformation. ${ }^{16-18}$ It should also be noted that mechanical treatment with diamond burs can cause microstructural changes in the Y-TZP ceramic, resulting in the formation of three well-defined layers, namely the crystallized surface zone $(10 \mathrm{~mm}$ to $20 \mathrm{~nm}$ particle diameter), the plastically-deformed zone, and the tetragonal-to-monoclinic phase transformation zone. ${ }^{19}$

Considering that zirconia exhibits a monoclinic phase up to $1170^{\circ} \mathrm{C}$ and a tetragonal between 1170 and $2370^{\circ} \mathrm{C},{ }^{20}$ sintering at $1550^{\circ} \mathrm{C}$ following diamond bur abrasion can result in reversal of the possible transformation to the monoclinic phase caused by tensions generated during the mechanical treatment. This, in turn, can restore stability to the structure without interfering with the abrasion-induced roughness, thereby justifying such a surface treatment.

Particle blasting on the zirconia surface is also commonly employed in attempts to improve bond strengths. ${ }^{12}$ Although previous studies have reported that the particle size does not interfere with the micromechanical retention of the restoration, ${ }^{21-23}$ we found that in the JAT group, which received blasting with $100 \mu \mathrm{m}$ glass particles, low bond strengths similar to those of the control group were obtained. It is therefore possible that the particle size has a negative effect on the bond strength, as larger particles can cause excessive roughness on the zirconia surface. This can then generate tension in the modified region, in addition to an increase in porosity, which causes a reduction in the cohesive strength of the ceramic and also in the strength of the resin cement. ${ }^{24}$ Furthermore, it was previously reported that mechanical treatment by blasting with glass particles less than $50 \mu \mathrm{m}$ 
(Cojet; 3M -ESPE St. Paul, Minnesota, United States) promoted micro-retentions on the surface, which resulted in a greater susceptibility to silane conditioning. ${ }^{8}$

In addition to particle blasting, we also evaluated the influence of mechanical conditioning using the milling machine employed for the preparation of the zirconia copings (Zirkonzahn Gais, Italy). This could be considered a simplified surface treatment, as it could be performed during the milling process. However, similar results to the control group and the particle-blasted group were obtained in the absence of a primer, while in the presence of a primer, the results were not superior to those obtained for any other treatment method examined.

Previous studies have also reported improved bond strengths through a combination of mechanical and chemical conditioning of the ceramic surface, and in particular where solutions containing phosphate monomers are employed for chemical conditioning. ${ }^{25-27}$ Thus, we herein employed Monobond Plus primer for chemical conditioning. This primer is composed of the phosphate monomer 10-methacryloyloxydecyl dihydrogen phosphate and the 3- (trimethoxysilyl) propyl methacrylate monomer, where the synergism between the two monomers increases the bond strength between zirconia and the resin cement. ${ }^{8}$ Indeed, we found that primer application was beneficial in terms of the microshear strength for the majority of samples following 24 hours and 60 days storage. This can be accounted for by considering that at the bonding interface between the Y-TZP ceramic and the resin cement, the phosphate monomers bind to the zirconium oxide layer via Van der Waals interactions or hydrogen bonds, which likely improve the wettability and chemical affinity of the Y-TZP ceramic, thereby promoting bonding to the self-adhesive resin cement.

Although several studies have reported promising results following surface conditioning of the Y-TZP ceramic, the proposed methodologies are often complex, in addition to being expensive and promoting tensions within the material, which can ultimately lead to failure in the adaptation of the prosthetic and subsequent bond instability. ${ }^{9,13,28}$ Our proposed ceramic surface roughening method based on diamond bur abrasion therefore proved to be an interesting alternative, as it is a simple and inexpensive technique. Indeed, our results confirmed that the diamond bur abrasion of Y-TZP ceramics during the pre-sintering period improved bond strengths. Furthermore, the combination of this method with the application of a primer would be expected to increase the clinical success rate for this type of restoration. We also note that following a 60 days aging period, the bond strengths of the PMM and Control samples that had been subjected to chemical conditioning were superior to those of the PMA group and similar to those of the JAT group.

Although laboratory tests cannot reproduce clinical conditions exactly, they are a major analysis parameter, because efficient in vitro performance may imply effective clinical performance. The results of this study therefore indicate that PMM surface preparation may provide greater mechanical strength in the oral environment after long periods, as those samples exhibited higher bond strength values after
24 hours storage than the other groups with previous chemical conditioning. However, randomized clinical trials will be needed to evaluate this surface treatment under more realistic conditions.

\section{Conclusion}

Based on the results of the present study, the use of primer improved the bond strength of the JAT and PMM groups after 24 hours and in all groups after 60 days.

The association of chemical conditioning and surface preparation after 24 hours of storage significantly improved the bond strength values only for the PMM group.

After 60 days of storage, the JAT group showed similar values among all groups, while the comparison between the other groups revealed higher values for the JAT and PMM groups and lower values for the PMA group.

\section{Conflict of Interest}

None declared.

\section{Acknowledgments}

We thank Coordenadoria de Aperfeiçoamento de Pessoal de Nível Superior (CAPES; Brasília, Brazil) for providing financial support.

\section{References}

1 Stawarczyk B, Frevert K, Ender A, Roos M, Sener B, Wimmer T. Comparison of four monolithic zirconia materials with conventional ones: Contrast ratio, grain size, four-point flexura strength and two-body wear. J Mech Behav Biomed Mater 2016;59:128-138

2 Gallina BL, Busato MCA, Sicoli EA, Camilotti V, Mendonca MJ. Aged translucent esthetic zirconia: bond strength analysis. Eur J Dent 2019;13(1):5-10 ahead of print

3 Inokoshi M, Vanmeensel $\mathrm{K}$, Zhang F, et al. Aging resistance of surface-treated dental zirconia. Dent Mater 2015;31(2):182-194

4 El-Shrkawy ZR, El-Hosary MM, Saleh O, Mandour MH. Effect of different surface treatments on bond strength, surface and microscopic structure of zirconia ceramic. Future Dental Journal. 2016;41:e53

5 Özcan M, Vallittu PK. Effect of surface conditioning methods on the bond strength of luting cement to ceramics. Dent Mater 2003;19(8):725-731

6 Melo RM, Souza RO, Dursun E, Monteiro EB, Valandro LF, Bottino MA. Surface treatments of zirconia to enhance bonding durability. Oper Dent 2015;40(6):636-643

7 Özcan M, Bernasconi M. Adhesion to zirconia used for dental restorations: a systematic review and meta-analysis. J Adhes Dent 2015;17(1):7-26

8 Inokoshi M, Kameyama A, De Munck J, Minakuchi S, Van Meerbeek B. Durable bonding to mechanically and/or chemically pre-treated dental zirconia. J Dent 2013;41(2):170-179

9 Tzanakakis EG, Tzoutzas IG, Koidis PT. Is there a potential for durable adhesion to zirconia restorations? A systematic review. J Prosthet Dent 2016;115(1):9-19

10 Kurtulmus-Yilmaz S, Aktore H. Effect of the application of surface treatments before and after sintering on the flexural strength, phase transformation and surface topography of zirconia. J Dent 2018;72:29-38

11 Ebeid K, Wille S, Salah T, Wahsh M, Zohdy M, Kern M. Evaluation of surface treatments of monolithic zirconia in different sintering stages. J Prosthodont Res 2018;62(2):210-217 
12 Ramos-Tonello CM, Trevizo BF, Rodrigues RF, et al. Pre-sintered Y-TZP sandblasting: effect on surface roughness, phase transformation, and Y-TZP/veneer bond strength. J Appl Oral Sci 2017;25(6):666-673

13 Inokoshi M, De Munck J, Minakuchi S, Van Meerbeek B. Meta-analysis of bonding effectiveness to zirconia ceramics. J Dent Res 2014;93(4):329-334

14 De Munck J, Mine A, Poitevin A, et al. Meta-analytical review of parameters involved in dentin bonding. J Dent Res 2012;91(4):351-357

15 Pereira GKR, Fraga S, Montagner AF, Soares FZM, Kleverlaan CJ, Valandro LF. The effect of grinding on the mechanical behavior of Y-TZP ceramics: A systematic review and meta-analyses. J Mech Behav Biomed Mater 2016;63:417-442

16 Jing Z, Ke Z, Yihong L, Zhijian S. Effect of multistep processing technique on the formation of micro-defects and residual stresses in zirconia dental restorations. J Prosthodont 2014;23(3):206-212

17 Pereira GK, Amaral M, Simoneti R, Rocha GC, Cesar PF, Valandro LF. Effect of grinding with diamond-disc and -bur on the mechanical behavior of a Y-TZP ceramic. J Mech Behav Biomed Mater 2014;37:133-140

18 Pereira GKR, Silvestri T, Camargo R, et al. Mechanical behavior of a Y-TZP ceramic for monolithic restorations: effect of grinding and low-temperature aging. Mater Sci Eng C 2016;63:70-77

19 Muñoz-Tabares JA, Jiménes-Piqué E, Reyes-Gasga J, Anglada M. Microstructural changes in ground 3Y-TZP and their effect on mechanical properties. Acta Mater 2011;59:6670-6683

20 Chevalier J, Gremillard L, Virkar AV, Clarke DR. The tetragonal-monoclinic transformation in zirconia: lessons learned and future trends. J Am Ceram Soc 2009;92:1901-1920
21 Ozcan M, Nijhuis H, Valandro LF. Effect of various surface conditioning methods on the adhesion of dual-cure resin cement with MDP functional monomer to zirconia after thermal aging. Dent Mater J 2008;27(1):99-104

22 Gomes AL, Castillo-Oyagüe R, Lynch CD, Montero J, Albaladejo A. Influence of sandblasting granulometry and resin cement composition on microtensile bond strength to zirconia ceramic for dental prosthetic frameworks. J Dent 2013;41(1):31-41

23 Valentino TA, Borges GA, Borges LH, Platt JA, Correr-Sobrinho L. Influence of glazed zirconia on dual-cure luting agent bond strength. Oper Dent 2012;37(2):181-187

24 de Jager N, Feilzer AJ, Davidson CL. The influence of surface roughness on porcelain strength. Dent Mater 2000;16(6):381-388

25 Inokoshi M, Poitevin A, De Munck J, Minakuchi S, Van Meerbeek B. Bonding effectiveness to different chemically pre-treated dental zirconia. Clin Oral Investig 2014;18(7):1803-1812

26 Mirmohammadi H, Aboushelib MN, Salameh Z, Feilzer AJ, Kleverlaan CJ. Innovations in bonding to zirconia based ceramics: Part III. Phosphate monomer resin cements. Dent Mater 2010;26(8):786-792

27 Yi YA, Ahn JS, Park YJ, et al. The effect of sandblasting and different primers on shear bond strength between yttria-tetragonal zirconia polycrystal ceramic and a self-adhesive resin cement. Oper Dent 2015;40(1):63-71

28 Pozzobon JL, Pereira GKR, Wandscher VF, Dorneles LS, Valandro LF. Mechanical behavior of yttria-stabilized tetragonal zirconia polycrystalline ceramic after different zirconia surface treatments. Mater Sci Eng C 2017;77: 828-835 